\title{
Patrimoine religieux en Languedoc-Roussillon
} (1789-1914)

\section{Philippe Goujard}

\section{OpenEdition}

1 Journals

Édition électronique

URL : https://journals.openedition.org/ahrf/7363

DOI : 10.4000/ahrf.7363

ISSN : 1952-403X

\section{Éditeur :}

Armand Colin, Société des études robespierristes

\section{Édition imprimée}

Date de publication : 1 septembre 2006

Pagination : 213-214

ISSN : 0003-4436

\section{Référence électronique}

Philippe Goujard, «Patrimoine religieux en Languedoc-Roussillon (1789-1914) », Annales historiques de la Révolution française [En ligne], 345 | juillet-septembre 2006, mis en ligne le 08 juillet 2008, consulté le 01 juillet 2021. URL : http://journals.openedition.org/ahrf/7363; DOI : https://doi.org/10.4000/ahrf. 7363

Ce document a été généré automatiquement le 1 juillet 2021.

Tous droits réservés 


\title{
Patrimoine religieux en Languedoc- Roussillon (1789-1914)
}

\author{
Philippe Goujard
}

\section{RÉFÉRENCE}

Géraldine Coudray-Bapsolle, Patrimoine religieux en Languedoc-Roussillon (1789-1914), Paris, L'Harmattan, 2005, 625 p., ISBN 2-7474-8983-8, $48 €$.

1 On est déçu par la lecture de ce livre qui traite du destin des lieux de culte des six plus grandes villes - plus de 10000 habitants en 1789 - du Languedoc-Roussillon : Béziers, Carcassonne, Nîmes, Montpellier, Narbonne et Perpignan. Seuls ont été pris en compte les lieux de culte catholiques : sélection étrange pour cette région, à moins qu'elle ne soit l'effet d'un parti pris. Le grand - seul ? - intérêt de ce travail est de s'appuyer sur une source méconnue des historiens du patrimoine, les archives de l'armée, stationnées à Vincennes. Mais l'auteur aurait pu éclairer de façon neuve l'aventure des églises paroissiales, chapelles, monastères et couvents, s'il n'avait cédé à la manie aujourd'hui obsessionnelle de voir dans la Révolution l'origine de tous les maux qui affectent la société française, et même pour certains la planète entière: refus obstiné des "réformes", violences dans certaines banlieues, déperdition de l'orthographe et bientôt, soyons en sûrs, ravages de l'obésité. Symptomatique, le titre de la première partie du premier chapitre "La ruine du patrimoine», qu'ouvre une partie intitulée «L'iconoclasme révolutionnaire ». L'auteur ne pense guère plus loin que Monsieur Taine. Il est regrettable qu'il n'ait pas ses talents de plume.

2 Seul point où je dirai mon accord avec l'esprit de ce livre : fidèle à Georges Clémenceau, l'auteur considère que «la Révolution est un bloc ». Dès la nationalisation des biens du clergé, tout ne fut que volerie, saccage, pillage. Dès 1790 en effet, les lieux de culte désaffectés furent bradés à des aigrefins, et les églises maintenues dans leur fonction dépouillées de leurs objets de culte et de leur mobilier sacré. Est-il besoin de dire que les années 1793-1794 furent l'apothéose de cette furie destructrice, œuvre de 
«proconsuls [sic] décidés » (p. 30), agissant avec l'appui des armées révolutionnaires, des municipalités et de hordes d'énergumènes dont on devine, car l'auteur ne nous dit rien de leur identité sociale, de quelle tourbe fangeuse ils devaient forcément surgir en ces temps où l'anarchie hystérique était à l'ordre du jour ? Pire encore, on célébra en ces saints lieux le culte de la Raison puis de l'Être suprême : on se demande au reste comment ces cultes purent se dérouler en des bâtiments dont l'auteur nous a dit auparavant que des furieux en avaient détruit les toits et les murs. Et, si la Révolution inventa le patrimoine, ce ne fut qu'une invention verbale d'une infime minorité. Dieu merci, vint la Restauration, respectueuse du passé chrétien de la France, fille aînée de l'Église.

3 Au total, ce livre s'inscrit dans le courant dominant, et bientôt unique si on n'y prend garde, de l'histoire -si j'ose dire- de la Révolution française. Sur les origines et les raisons de cette hégémonie, beaucoup a été dit, et bien dit. Je me permettrai une observation. Il conviendrait en effet de se demander si ce rejet de la Révolution n'est pas obligation d'oubli d'un grand moment qui fut, mais précisément parce qu'il fut une période de rupture et de conflits, fondateur de notre ordre politique et social, lequel a aujourd'hui besoin pour exister de consensus et par conséquent besoin d'un discours qui évite ou élimine tout ce qui peut rappeler la notion de conflit quels que soient son objet et sa nature. 